better service as well as reduced cost.

Libraries which serve as designated depositories for government publications know of the improvements that have taken place in the depository distribution program. The issuance of the Classified List in individual card form, the daily depository shipping list, and the survey of the depositories for the selection of new series of publications are among the changes to which we have had a most favorable reaction.

There is strong evidence that librarians, too, think about government costs. Although they are experts in knowing where and how to acquire publications without charge, they are also surprisingly prominent among the regular purchasers of government publications from the Superintendent of Documents. $\mathrm{Li}$ brarians are also active in assisting patrons in placing orders for the purchase of government publications. The fine work which some libraries are doing in the display of our price lists and sales announcements is producing an ever-widening circle of users of official publications and an increasing number of libraries is experimenting with the actual sale of government publications to provide a new and valuable service to their communities.

Since 1939, the number of publications sold has increased more than 300 per cent, and the trend is still upward. Last year more orders for publications were received than ever before in the history of the Division of Public Documents. There can be no question that a large part of this increase in interest in government publications, when reading is supposed to be slipping into the lost arts in favor of radio, movies, and television, can be attributed directly to the efforts of librarians.

In these troublesome days, it is a healthful sign for our entire way of life that more and more people are reading more and more reports on the policies and activities of their government. Now, as never before, it is vital for citizens to be informed, and the job of obtaining information should be made as easy as possible. Great progress has been made in making the content of government publications more understandable and the format more attractive and readable. But at best, government reports will not attract spontaneous readership. The librarian will continue to be a potent force in making government publications available to the serious reader. $\mathrm{He}$ must accept the challenge of broadening recognition of the value of a class of material which, although difficult to handle, presents the results of the extensive research and study by government experts in practically every field of human endeavor. Dissemination of this information is also a challenge to us in the Division of Public Documents, and we pledge cooperation with the library profession in the task of meeting the challenge.

\title{
The Indexing and Distribution of Census Publications
}

Mr. Ullman is chief, Statistical Reports Section, U.S. Bureau of the Census.

S MOST of You KNow, the Bureau of the
gathering and reporting information needed
by government, by business, by research work-
ers, and by the general public. Acting under
Congressional mandate, we issue a continu-
ous stream of statistical reports on such topics
as business, industry, foreign trade, govern-
ments, agriculture, housing and, of course,
population. From time to time we present
the results of our research on techniques or
special applications in such reports as the recent Indexes of Production ${ }^{1}$ published jointly by the Bureau of the Census and the Federal Reserve Board. All in all, our annual publications output fluctuates from a minimum of 12,000 pages to a maximum of 60,000 or more when reports for a major census are issued.

With a flow of material of this variety and magnitude, it is obvious why we, ourselves, need library aids to record our output. General users of our material, such as the li-

\footnotetext{
${ }^{1}$ Census of Manufactures: 1947, Indexes of Production, Joint publication of U.S. Bureau of the Census and Board of Governors of the Federal Reserve System, U.S. Government Printing Office, Washington 25, D.C.
} $\$ 1.75$. 
brarians, need these library tools and devices even more. We are also aware that reference to a title is not enough in handling statistical material, because the need is most often for a particular type of data, which is not revealed, except in a general sense, in the title. This need for detail is, I believe, characteristic of the use of reference volumes in general and statistical publications in particular.

\section{AIDS FOR FINDING STATISTICAL DATA}

The Bureau of the Census issues two series of publications which are of help in the search for specific data. The first is the Statistical Abstract of the United States ${ }^{2}$ and its supplements, and the second is the Catalog of United States Census Publications. ${ }^{3}$

The Statistical Abstract, issued annually since 1878 , brings together in one book the principal statistics on the United States from all sources, governmental and nongovernmental. The sources in the 1952 edition, for example, include 74 governmental agencies and 42 nongovernmental groups. Below each of the 1085 tables, the source of the information is cited. Thus, to find a particular item, you can locate a table on the subject with the aid of the table of contents or the highlydetailed index. The table may give the data you need. If not, the source at the bottom of the table indicates where to look for more detail. This technique appears to be effective in covering most important sources of national data.

The two supplements to the Abstract can be used in similar fashion, since the same principles governed their preparation. The Abstract is restricted by the objective of keeping it a one-volume edition. It emphasizes current data and includes only a limited amount of historical data. To meet needs for more historical detail, the Bureau of the Census, in cooperation with the Social Science $\mathrm{Re}$ search Council, published, in 1949, Historical Statistics of the United States, I789-1945.* This book presents annual detail for most of the 3000 series which it includes. Coverage and source annotation follow the Abstract

${ }^{2}$ U.S. Bureau of the Census, Statistical Abstract of the United States: I952. Washington, D.C., I952

(latest edition). $\$ 3.25$.
3 U.S. Bureau of the Census, Catalog of United States Census Publications, 1952. Washington, D.C., I 953 (latest edition).

${ }_{4}$ U.S. Bureau of the Census, Historical Statistics of the United States, I789-I945, Washington, D.C., I 949. $\$ 2.75$. pattern. A historical appendix to recent editions of the Abstract brought up to date many of the time series in Historical Statistics, but this appendix will be omitted from the 1953 and future editions. Present plans call for a separate pamphlet to continue these series, and a revision of Historical Statistics in 1956.

Similarly, the need for statistics in some geographic detail is met by a second supplement, the County and City Data Book. ${ }^{5}$ In the 1952 edition, the latest, more than 125 items are presented for each county and for each city with 25,000 or more inhabitants. Data are summarized for standard metropolitan areas and for states. Again, scope and source are in the Abstract tradition. The bureau plans to issue a new edition of this book about three times a decade, as major census programs make new county and city detail available.

To meet the need for most formal listings, the Bureau of the Census issues a quarterly Catalog of U.S. Census Publications, with monthly supplements. This Catalog lists completely all publications issued by the bureau in the period covered. It describes fully the contents of each publication, so that this description can be indexed and used as a guide to the data in census publications. The index is divided into two parts-a geographic area index and a subject index.

Each quarterly catalog is cumulative to an annual catalog which covers the calendar year. The series of annual catalogs starts with 1946 . Census publications prior to 1946 are listed in the volume, Catalog of U.S. Census Publications, $1790-1945^{6}$ published jointly by the Bureau of the Census and the Library of Congress. This series of catalogs thus provides a complete listing of all census publications since the first decennial census in 1790 . You may be interested to know that microfilm copies of all publications from 1790 through 1890 are available to libraries and others, at cost.

The monthly supplement to the Catalog is a means of telling the public relatively quickly what census reports have been issued. Regular quarterly and monthly reports are not mentioned unless a change in the series occurs.

5 U.S. Bureau of the Census, County and City Data Book, I952, Washington, D.C., I 953 (latest edition). $\$ 4.25$.

${ }^{6}$ U.S. Bureau of the Census and U.S. Library of Congress, Catalog of United States Census Publications, I790-I945, by Henry J. Dubester. Washington, D.C., I 950 . \$I.50. 
Descriptive matter and other information which might delay publication is also omitted.

The appendix to the annual Catalog is also used to provide finding aids to help in handling census inquiries. Two examples are the listing of Facts for Industry reports in the appendix to the 1948 Catalog, and the statement of census policy on special tabulations and other special work in the appendix to the 1952 Catalog. If librarians will tell us of possible similar aids, we may be able to make them available. We should also like to know about the devices you have developed to simplify your handling of statistical reports.

Other techniques are also used to inform the public of census reports. Flyers are prepared and distributed for important reports. Press releases are also issued. The reports are listed in the Monthly Catalog of the Superintendent of Documents and the weekly Business Service Check List of the Department of Commerce. Beyond this, however, the announcements, listings, and reviews are rather sporadic. For example, there is no systematic listing in such sources as $P u b$ lisher's Weekly or the New York Times book review section, since these publications do not regularly cover government reports; nor does the government have any provision for bringing its publications into more prominent notice.

\section{DISTRIBUTION OF CENSUS REPORTS}

Listings, catalogs, and announcements call attention to publications, but without the actual publications, they are of limited value. Let us discuss briefly, therefore, the distribution of census reports, especially in relation to libraries.

When a government agency sends a report to the Government Printing Office for printing, it asks for a limited supply for official use and it estimates the potential sales. The Superintendent of Documents then decides how many copies should be printed. The price of the report to the public is based on the cost of printing and distributing. It does not cover the cost of preparing the contents or of printing the first copy. These factors are considered part of the function of carrying out the Congressional mandate and are therefore charged to the government agency. Thus, when you buy a report from the Superintendent of Documents, you pay only for the cost of the paper and the labor needed to provide you with a separate copy. But each report sent to the printer means a cost to the government agency involved.

The publications printed on the facilities of the Department of Commerce are similarly handled. The appropriations cover the basic work and the printing of copies for official use. Those who wish to have an individual report pay for the extra expense incurred in providing that additional copy.

No doubt, many of you remember when you could get a free copy of a publication by writing to the government agency or to your Congressman. You may have noticed that, increasingly, the reply to such a request indicates that the publication is available from the Superintendent of Documents and quotes the price. In general, it is now a matter of principle and practice to make census and other government publications available to the public only through purchase.

The reasons for this change are obvious. Congressmen and government administrators are conscious of the high level of the federal budget and of federal taxes. In reviewing appropriations to find means of reducing your tax burden, Congressmen question the expenditure of funds to distribute large numbers of reports. In the last hearings on appropriations for the Department of Commerce, the committee even discussed the possibility of including in the price of the report some part of the cost of preparing the contents.

Another factor which makes publications more prominent as a source of government revenue is the increase in cost. In 1930, Volume I of the Census of Population sold for $\$ 2$. In 1950, the price of the corresponding volume is $\$ 7$. A complete set of the final reports on population, housing, and agriculture in 1940 would have cost about $\$ 150$. The corresponding reports for 1950 are listed at $\$ 350$. In 1942 , the sale of census publications brought in about $\$ 50,000$. The corresponding sales in 1952 were over a quarter of a million dollars.

The increased emphasis on government economy and the rising cost of printing also tend to limit the distribution of reports for official use in another manner. As each agency's appropriation is pared to a workable minimum and as rising costs force stricter economy, government administrators examine their programs for all possible economies. They have increasingly tended to define "official use" in a more limited manner. To il- 
lustrate the effects of this action, if the officials of the Bureau of the Census can reduce by 100 the number of sets of 1950 census reports for official use, they thereby eliminate the printing of reports that would sell for $\$ 35$,00o. These savings can be used for the preparation of additional data which would otherwise be eliminated.

The development of this emphasis on sales of government reports should not reduce their use. A person who has been receiving a copy without cost must now reexamine his need for that publication. If his need is not sufficient to warrant the price of the report, the cost to the government is saved. If he needs the report, he will evaluate the cost against that need and decide whether to purchase the report or use a library copy. In the same way, those libraries which are not depositories and which operate on limited budgets must evaluate the price of the report against its potential use.

To help the prospective purchaser evaluate the report, he should have an opportunity to inspect a copy. Furthermore, it is easier for the Bureau of the Census to refer a person requesting information to a copy of the report than to include detailed information in a letter. As a matter of administrative convenience, therefore, current census reports should be available to the public at strategic locations.

Consideration must also be given to the fact that census reports are current history and the raw material for many types of research. Long after supplies of a report are distributed, requests for it are received. The bureau could not maintain stocks of publications to meet such requests. Furthermore, full answers to the questions of research workers would be quite expensive and probably inadequate, since the research worker would probably wish to examine the complete report, to read the background material, and to examine related data. For reference and research purposes, therefore, collections of census reports should be conveniently placed.

For these reasons the Bureau of the Census includes, in its official distribution of reports, a supply of copies to build up collections of census reports in selected libraries throughout the country.

Let us consider briefly what is involved in the official distribution of reports. First of all, copies are needed by the Bureau of the
Census in its own work. Copies are also furnished to other government agencies whose work is closely related to the subject-matter of the census. In particular, copies are furnished to agencies which need the information immediately. Copies of the report are also furnished to various public relations media, such as newspapers, radio stations, trade journals, etc., to encourage making the data available. One of the principal channels through which census information reaches the public is through re-publication in newspapers and the trade press. Copies may also be furnished to persons or agencies who cooperated with the bureau in planning the particular survey which resulted in the report.

This now leaves us with the problem of insuring that reference and research collections are established for current and for future use. This function also involves helping libraries handle reports properly. For this reason we are careful to arrange our reports in series and to include inforn ation in each publication which will help relate that publication to others in that series. This type of service should be improved now that the Census Library has been re-established. Louise Clickner, for many years head of the Municipal Reference Service within the bureau, is now Census Librarian. One of the purposes of this library is to act as a complete depository of census publications. As our own collection develops and the organization improves, we will be in a better position to provide library aid for historical as well as current census materials.

In distributing our publications, we should first mention that a copy of every report published by the bureau is sent to each of the field offices of the Department of Commerce. The function of these offices is to provide service to businessmen and census reports are useful in solving business problems. This distribution makes current reports available for examination in 42 cities. Since these offices also act as agents for the Superintendent of Documents, publications can be purchased directly through them.

\section{GOVERNMENT DEPOSITORY LIBRARIES}

At this point, too, the government depository libraries should be mentioned. As you know, this system of libraries was created by the Congress and is supplied with government reports through the Superintendent of Docu- 
ments. Distribution to these libraries is therefore independent of distribution by the Bureau of the Census. However, the availability of census publications in these libraries has to be considered when we discuss the location of census collections.

We find that, of the 544 government depository libraries, 538 receive one or more of the classes of census publications; I43 receive every census ieport distributed by the Superintendent of Documents; and another 185 receive all except two or three of the 34 classes of census reports. For most purposes, therefore, we can say that 328 government depository libraries have virtually complete sets of census reports. If we were to add the number that receive only the final reports of certain major censuses, and therefore have collections suitable for historical research, this number would be increased by another hundred or more.

This, then, would appear to provide a sizable network of libraries having census reports. When we consider, however, what we expect from libraries which maintain collections of our reports, we find certain weaknesses.

In communicating with the general public, we should like to be able to refer them to libraries where the publications are always accessible. Libraries which are open only to certain groups or at certain times of the year, such as some college libraries, do not always meet this condition. We should like our reports to be located in areas of population concentration where they will be effectively used. For example, every city with 50,000 or more inhabitants should have a collection of census reports and every university with 5,000 or more students should probably have a similar collection either on the premises or conveniently accessible. Furthermore, we should like these libraries to be of sufficient size and to have sufficient staff to provide adequate service to the public. We are also concerned with keeping such collections as efficiently distributed as possible, so we limit free sets to one for an institution, and a minimum number in any one area. If additional sets are needed within the institution or within the area, for a branch or a subdivision of the library, we feel that the cost of the extra publications should be a normal charge against library operation rather than a levy against the government.

\section{CENSUS LIBRARIES}

The Bureau of the Census therefore supplements the government depository library system by furnishing copies of census publications to an additional group of libraries, which we label "census" libraries. This system reached a peak in 1943 when sets of census reports were furnished to 425 libraries, and the statement was made that a set of census reports could be found within 200 miles of every person in the country. As wartime pressures eased and libraries were asked each year whether they wished to continue to receive these reports, the number gradually dwindled to less than 200 libraries. These libraries were furnished, during 1952, with about 72,000 items with a total list cost of more than $\$ 33,000$. The cost of maintaining this service to libraries amounts to from $\$ 10,000$ to $\$ 35$,000 per year depending upon the publication load.

To justify the investment in this system we undertook to re-examine our objectives and the choice of libraries in this system several years ago. In this undertaking, members of the ALA have been very helpful. The locations of government depository libraries with relatively complete collections of census reports were examined in relation to population distribution, size of library budget and staff, the existence of other library facilities in the area, and related factors. The result of our examination reveals that we could reduce the number of census libraries to approximately I 20 and still provide, in conjunction with the government depository system, a network of reference collections more than adequate for our purposes. There would be such a collection in a well-equipped library in every state, and in every city with 50,000 or more persons. Every college with 2,00o or more students would have such a collection or would have the volumes available in the area. In short, our present system could be made more efficient and result in a savings of approximately 25 per cent of our present expenditure for this purpose.

We have not yet instituted these changes, for there are as yet a number of policy matters to be decided. We should like to know more about the effectiveness of library service in various areas and under various conditions of staffing. There are also problems with regard to historical research, for we do not as yet know the extent of the census collections in 
various places. However, when such changes do take place, we shall furnish full information to those libraries which will be affected and request their consideration and cooperation.

In summary, let me state that the Census Bureau will continue to issue the statistical reports which you use in your reference work with the same care and consideration that has governed the preparation of these reports in the past. It will continue to prepare and issue the catalogs, announcements and other material which will help you use these publica- tions, and, if you indicate your needs in the way of finding media and other aids, we will prepare and furnish them to the extent that our facilities permit. We will continue to encourage the maintenance of strategically placed collections of census publications and rely on the librarians, in turn, to make these collections available to the public and to encourage their use. Finally we shall appreciate any suggestion for the improvement of our publications from the principal retailers of our data, the librarians.

\section{By JAMES H. MACBRIDE}

\section{A Subject Approach to United Nations Documents}

Mr. MacBride is research librarian, Michigan State College.

A BIBLIOGRAPHY of some proportion is growing around the documents issued by the United Nations and its Specialized Agencies. ${ }^{1}$ However the viewpoint taken by nearly every author in the past has been descriptive in nature. Thus we have a list of sources, exclusive of certain official documents of the Secretariat, the United Nations Library, and the United Nations Archives, which gives us sufficient detail concerning types of documents, associated symbols, and organs of issuance. It should be pointed out that the stress has been placed on the mimeographed document originating from sources within the United Nations proper. The publications of the Specialized Agencies have been somewhat neglected. The printed document, other than the various Official Records, has received even less attention although it presents problems of equal magnitude, if somewhat different in nature. Mr. Jerome $\mathrm{K}$. Wilcox of the City College of New York has. suggested that the gap which exists at present in the above bibliography in regard to the Specialized Agencies might well be a subject for future research. ${ }^{2}$

After having visited a few libraries in the

1 Moor, Carol Carter and Chamberlain, Waldo, How to Use United Nations Documents, New York, New York University Press, 1952, p. 22.

${ }^{2}$ Letter to J. H. MacBride dated April 29, 1953. Mr. Wilcox points out that ". . a paper ... (on) the Care, Treatment, and Handling of United Nations Specialized Agency Material by Designated Depository Libraries ..." would be both new and useful.
East, the Mid-West, and the West, it is believed that there is a felt need for a more definitive line of approach to the research and reference use of all of the United Nations documents. ${ }^{3}$ Specifically the need as expressed is not one of description or organization but rather one for tools for use in entering the large mass of variegated material quickly and easily. Many questions might be raised at this point, but let us begin with an assumption: the documents of the United Nations and of the Specialized Agencies should not be separated from one another, but instead should be placed if not in a collection at least in a common shelf area. This point is vital in terms of ready physical and subject access to both the documents and the information contained in them. Separation of the documents into the stack area under various systems of classification means $I$. that full cataloging is necessary, 2. that time is wasted in securing the documents, and 3. that related pieces of information are frequently "lost" to the reader through being so far dispersed in space or in the catalog. Therefore, acting under this assumption, logical and pragmatic considerations demand that we emphasize:

I. the basic importance of the mimeographed document

2. the binding of these documents and of the

3 The libraries visited were those of Harvard College, Massachusetts Institute of Technology, Yale University, City College of New York. New York University, The United Nations Library, University of Pennsylvania, University of Michigan, University of Illinois, Wash. ington State College, University of Colorado, Los Angeles Public Library. However, unless stated otherwise, the views in this article are those of the author. 